\title{
Disparity on Unplanned Readmission in Melanoma Patients: A National Cancer Database Analysis
}

\author{
DANIEL BOCZAR ${ }^{1}$, DAVID J. RESTREPO ${ }^{1}$, ANDREA SISTI ${ }^{1}$, MARIA T. HUAYLLANI ${ }^{1}$, \\ AARON C. SPAULDING ${ }^{2}$, EMMANUEL GABRIEL ${ }^{3}$, SANJAY BAGARIA $^{3}$, \\ ALEXANDER S. PARKER ${ }^{4}$, AARON L. LEPPIN ${ }^{5}$ and ANTONIO J. FORTE ${ }^{1}$ \\ ${ }^{1}$ Division of Plastic Surgery, Mayo Clinic, Jacksonville, FL, U.S.A.; \\ ${ }^{2}$ Robert D. and Patricia E. Kern Center for the Science of Health Care Delivery, \\ Mayo Clinic, Jacksonville, FL, U.S.A.; \\ ${ }^{3}$ Department of Surgery, Mayo Clinic, Jacksonville, FL, U.S.A.; \\ ${ }^{4}$ University of Florida, College of Medicine, Jacksonville, FL, U.S.A.; \\ ${ }^{5}$ Health Services Research, Mayo Clinic, Rochester, MN, U.S.A.
}

\begin{abstract}
Background/Aim: This study aimed to analyze associated factors of 30-day hospital readmission after surgery for melanoma. Patients and Methods: We conducted a retrospective analysis of postoperative 30-day unplanned readmission in patients with melanoma in the National Cancer Database (NCDB). Results: Higher odds of unplanned readmission were found in non-white patients compared to white, uninsured patients compared to those with private insurance, tumors with invasive behavior compared to in situ, presence of ulceration, American Joint Committee on Cancer stages greater than II, and location in the extremities. Lower odds of unplanned readmission were found in women living in areas where the percentage of adults who did not graduate from high school was below $13.0 \%$ with an annual income of $\$ 38,000$ or more, who were treated in Academic/Research Programs or Integrated Network Cancer Programs. Conclusion: Non-white patients and low-income zip-codes were associated with unplanned readmission.
\end{abstract}

The incidence of melanoma is rising, representing an important epidemiologic and health issue worldwide (1). Readmission is an important marker of care quality in the United States (2). Rehospitalization is a frequent and expensive event often due to flaws in post-discharge care.

Correspondence to: Antonio Jorge Forte, MD, Ph.D., Mayo Clinic Florida, 4500 San Pablo Road, Jacksonville, FL 32224, U.S.A. Tel: +1 9049532073, e-mail: ajvforte@yahoo.com.br

Key Words: Melanoma, length of stay/statistics \& numerical data, outcome and process assessment, patient readmission, quality of health care, disparities, surgical treatment.
The rate of readmission can be reduced with improvement of the health care system (3). To achieve that outcome, it is important to understand the factors associated with disparities in readmissions in the United States. Disparities in melanoma treatment across the country are a proven reality (4). In 2017, Ascha et al. (5) analyzed the factors associated with 30-day readmission following sentinel lymph node biopsy and lymphadenectomy after malignant melanoma.

This study sought to analyze all patients diagnosed with melanoma recorded in the National Cancer Database (NCDB), searching for factors associated with unplanned readmission after surgical discharge and eventual disparities in the population sample. We hypothesized that patient disparities impact 30-day unplanned surgical readmission in this study population.

\section{Patients and Methods}

For our study, we used the NCDB, an initiative driven by the American Cancer Society and the American College of Surgeons' Commission on Cancer that registers $70 \%$ of all cancer diagnoses in the United States (6). Our study was considered exempt from review by the institutional review board.

Eligible cases were identified using the NCDB Participant User File of melanoma patients. Data were extracted for all patients diagnosed with melanoma with recorded information regarding 30day hospital readmission following surgical discharge from January 1, 2004, to December 31, 2015. The cohort was then split into two groups based on hospital readmission (i.e., unplanned readmission or no unplanned readmission) (Table I). Patients who did not undergo a surgical procedure or for whom information about readmission was missing were excluded from this analysis.

Data were extracted on patient demographics, facility type, and tumor characteristics. Patient demographics included age, sex, race, income (i.e., median household income for area of 
Table I. Patient demographic and clinical data by presence or absence of unplanned readmission.

\begin{tabular}{|c|c|c|c|c|c|}
\hline \multirow[b]{2}{*}{ Variable } & \multicolumn{2}{|c|}{ No unplanned readmission } & \multicolumn{2}{|c|}{ Unplanned readmission } & \multirow[b]{2}{*}{$p$-Value } \\
\hline & No. & $\%$ & No. & $\%$ & \\
\hline Total & 485,528 & $98.9 \%$ & 5,216 & $1.1 \%$ & \\
\hline Age, mean (SD) & 61.38 & 16.146 & 62.29 & 16.273 & $<0.001$ \\
\hline Age & & & & & $<0.001$ \\
\hline $0-49$ & 110,609 & $22.8 \%$ & 1,173 & $22.5 \%$ & \\
\hline $50-59$ & 96,429 & $19.9 \%$ & 963 & $18.5 \%$ & \\
\hline $60-69$ & 113,044 & $23.3 \%$ & 1,130 & $21.7 \%$ & \\
\hline $70-79$ & 98,616 & $20.3 \%$ & 1,129 & $21.6 \%$ & \\
\hline $80+$ & 66,830 & $13.8 \%$ & 821 & $15.7 \%$ & \\
\hline Gender & & & & & $<0.001$ \\
\hline Male & 276,383 & $56.9 \%$ & 3,104 & $59.5 \%$ & \\
\hline Female & 209,145 & $43.1 \%$ & 2,112 & $40.5 \%$ & \\
\hline Income & & & & & $<0.001$ \\
\hline$<\$ 38,000$ & 48,388 & $10.0 \%$ & 765 & $14.7 \%$ & \\
\hline$\$ 38,000-\$ 47,999$ & 95,413 & $19.7 \%$ & 1,157 & $22.2 \%$ & \\
\hline$\$ 48,000-\$ 62,999$ & 131,373 & $27.1 \%$ & 1,418 & $27.2 \%$ & \\
\hline$>\$ 63,000$ & 206,227 & $42.5 \%$ & 1,824 & $35.0 \%$ & \\
\hline Unknown & 4,127 & $0.9 \%$ & 52 & $1.0 \%$ & \\
\hline Education & & & & & $<0.001$ \\
\hline$>21.0 \%$ & 44,275 & $9.1 \%$ & 669 & $12.8 \%$ & \\
\hline $13.0 \%-20.9 \%$ & 99,280 & $20.4 \%$ & 1,265 & $24.3 \%$ & \\
\hline $7.0 \%-12.9 \%$ & 168,535 & $34.7 \%$ & 1,773 & $34.0 \%$ & \\
\hline$<7.0 \%$ & 169,591 & $34.9 \%$ & 1,464 & $28.1 \%$ & \\
\hline Unknown & 3,847 & $0.8 \%$ & 45 & $0.9 \%$ & \\
\hline Population density & & & & & $<0.001$ \\
\hline Metro counties & 399,051 & $82.2 \%$ & 4,207 & $80.7 \%$ & \\
\hline Urban counties & 62,515 & $12.9 \%$ & 776 & $14.9 \%$ & \\
\hline Rural counties & 7,932 & $1.6 \%$ & 93 & $1.8 \%$ & \\
\hline Unknown & 16,030 & $3.3 \%$ & 140 & $2.7 \%$ & \\
\hline Race & & & & & $<0.001$ \\
\hline Caucasian & 472,640 & $97.3 \%$ & 5,041 & $96.6 \%$ & \\
\hline Non-Caucasian & 5,860 & $1.2 \%$ & 117 & $2.2 \%$ & \\
\hline Unknown & 7,028 & $1.4 \%$ & 58 & $1.1 \%$ & \\
\hline Insurance & & & & & $<0.001$ \\
\hline Private & 254,612 & $52.4 \%$ & 2,345 & $45.0 \%$ & \\
\hline Not insured & 9,813 & $2.0 \%$ & 163 & $3.1 \%$ & \\
\hline Government & 210,160 & $43.3 \%$ & 2,338 & $44.8 \%$ & \\
\hline Unknown & 10,943 & $2.3 \%$ & 370 & $7.1 \%$ & \\
\hline Facility type & & & & & $<0.001$ \\
\hline Community Cancer Program & 27,316 & $5.6 \%$ & 420 & $8.1 \%$ & \\
\hline Comprehensive Community Cancer Program & 157,026 & $32.3 \%$ & 2,179 & $41.8 \%$ & \\
\hline Academic/Research Program & 210,582 & $43.4 \%$ & 1,591 & $30.5 \%$ & \\
\hline Integrated Network Cancer Program & 39,599 & $8.2 \%$ & 508 & $9.7 \%$ & \\
\hline Unknown & 51,005 & $10.5 \%$ & 518 & $9.9 \%$ & \\
\hline
\end{tabular}

Chi square or Mann-Whitney test was used for the analyses.

residency), level of education (based on area of residency), insurance (i.e., private, uninsured, and government), and population density (i.e., metro counties, urban counties, rural counties). Facility characteristics included facility type. Tumor characteristics included invasive behavior, Breslow depth, American Joint Committee on Cancer (AJCC) stage, and presence of ulceration.

Patient demographics, facility type, and tumor characteristics were described and analyzed using $\chi^{2}$ or Mann-Whitney tests as appropriate. Multivariate analysis was performed using a logistic regression model to assess independent associations, adjusting for confounders. Separate analyses were conducted with the outcome variable being unplanned readmission and predicted variables being patient demographic and tumor characteristics (i.e., age, sex, race, income, education, insurance, AJCC stage, ulceration, behavior, and body location). The significance level was set at $p<0.05$. Statistical analysis was done using SPSS, version 25.0, statistical software (SPSS Inc.). 


\section{Results}

A total of 490,744 patients met the inclusion criteria of the study. The analyzed cohort included 485,528 (98.9\%) patients without unplanned readmission and 5,216 (1.1\%) with unplanned readmission. Unplanned readmission was more prevalent among non-white men older than 70 years, living in urban or rural counties and areas with an income lower than $\$ 47,999$ per year, where the percentage of adults who did not graduate from high school was above $12.9 \%$ $(p<0.001)$. On the other hand, unplanned readmission was less prevalent among patients with private insurance treated in Academic/Research Programs $(p<0.001)$ (Table I).

Higher odds of unplanned readmission were found in nonwhite patients compared to white, uninsured patients compared to those with private insurance, tumors with invasive behavior compared to in situ, presence of ulceration, AJCC stages greater than II compared to stage 0 , and location in the extremities compared to head and neck. Lower odds of unplanned readmission were found in women, living in areas where the percentage of adults who did not graduate from high school was below $13.0 \%$ compared to $21.0 \%$ or more, with an annual income of $\$ 38,000$ or more compared to less than $\$ 38,000$, and treated in Academic/Research Programs or Integrated Network Cancer Programs compared to Community Cancer Program (Table II).

\section{Discussion}

To our knowledge, this study is the largest series to date to delineate factors associated with unplanned readmission among melanoma patients. Patients diagnosed with melanoma in the United States over a 12-year span were more likely to have 30-day unplanned readmission if they had low socioeconomic status and were non-white. Therefore, our data illustrates the need for efforts to improve sociodemographic disparities in melanoma treatment.

This topic has been largely unexplored in the literature; however, a few smaller studies have analyzed factors such as insurance status. A study in 2017 that examined surgical treatment delays in patients with melanoma according to insurance type pointed out that people insured by Medicaid experienced delays in treatment in comparison to people insured by private companies and Medicare (7). A similar analysis identified melanoma patients insured by Medicaid to be more likely to manifest with advanced tumor and less likely to undergo curative treatment (8). In our analysis, uninsured patients were more likely to have a 30-day unplanned readmission compared to privately insured patients.

Timeline of swift diagnosis and expedited therapy is of utmost importance in cancer treatment as disparities in cancer care have been heavily studied based on type of
Table II. Odds of presenting unplanned readmission among melanoma patients.

\begin{tabular}{|c|c|c|c|c|}
\hline \multirow[b]{2}{*}{ Variables } & \multirow[b]{2}{*}{ OR } & \multicolumn{2}{|c|}{$95 \% \mathrm{CI}$} & \multirow[b]{2}{*}{$p$-Value } \\
\hline & & Lower & Upper & \\
\hline Age & 1.003 & 1 & 1.006 & 0.051 \\
\hline \multicolumn{5}{|l|}{ Gender } \\
\hline Male & 1 & \multicolumn{2}{|c|}{ Reference } & - \\
\hline Female & 0.92 & 0.868 & 0.975 & 0.005 \\
\hline \multicolumn{5}{|l|}{ Income } \\
\hline$<\$ 38,000$ & 1 & \multicolumn{2}{|c|}{ Reference } & - \\
\hline$\$ 38,000-\$ 47,999$ & 0.829 & 0.751 & 0.915 & $<0.001$ \\
\hline$\$ 48,000-\$ 62,999$ & 0.801 & 0.722 & 0.889 & $<0.001$ \\
\hline$>\$ 63,000$ & 0.764 & 0.681 & 0.858 & $<0.001$ \\
\hline Unknown & 1.855 & 0.868 & 3.965 & 0.111 \\
\hline \multicolumn{5}{|l|}{ Education } \\
\hline$>21 \%$ & 1 & \multicolumn{2}{|c|}{ Reference } & - \\
\hline $13 \%-20.9 \%$ & 0.969 & 0.877 & 1.07 & 0.53 \\
\hline $7 \%-12.9 \%$ & 0.891 & 0.803 & 0.99 & 0.031 \\
\hline$<7 \%$ & 0.822 & 0.73 & 0.925 & 0.001 \\
\hline Unknown & 0.441 & 0.193 & 1.008 & 0.052 \\
\hline \multicolumn{5}{|l|}{ Population density } \\
\hline Metro counties & 1 & \multicolumn{2}{|c|}{ Reference } & - \\
\hline Urban counties & 0.95 & 0.875 & 1.033 & 0.231 \\
\hline Rural counties & 0.822 & 0.666 & 1.015 & 0.068 \\
\hline Unknown & 0.798 & 0.659 & 0.965 & 0.02 \\
\hline \multicolumn{5}{|l|}{ Race } \\
\hline Caucasian & 1 & \multicolumn{2}{|c|}{ Reference } & - \\
\hline Non-Caucasian & 1.514 & 1.255 & 1.827 & $<0.001$ \\
\hline Unknown & 0.796 & 0.613 & 1.034 & 0.087 \\
\hline \multicolumn{5}{|l|}{ Insurance } \\
\hline Private & 1 & \multicolumn{2}{|c|}{ Reference } & - \\
\hline Not insured & 1.362 & 1.158 & 1.602 & $<0.001$ \\
\hline Government & 1.054 & 0.977 & 1.136 & 0.173 \\
\hline Unknown & 3.893 & 3.471 & 4.367 & $<0.001$ \\
\hline Behavior & & & & \\
\hline In situ & 1 & & & - \\
\hline Invasive & 1.448 & 1.188 & 1.765 & $<0.001$ \\
\hline Body location & & & & \\
\hline Head and neck & 1 & & & - \\
\hline Trunk & 0.975 & 0.901 & 1.055 & 0.525 \\
\hline Extremities & 1.14 & 1.061 & 1.226 & $<0.001$ \\
\hline Others & 1.751 & 1.419 & 2.161 & $<0.001$ \\
\hline Ulceration & & & & \\
\hline No & 1 & & & - \\
\hline Yes & 1.288 & 1.189 & 1.395 & $<0.001$ \\
\hline Unknown & 0.828 & 0.746 & 0.919 & $<0.001$ \\
\hline AJCC - tumor stage & & & & \\
\hline 0 & 1 & & & - \\
\hline I & 1.013 & 0.824 & 1.245 & 0.902 \\
\hline II & 1.255 & 1.012 & 1.557 & 0.039 \\
\hline III & 2.258 & 1.822 & 2.8 & $<0.001$ \\
\hline IV & 2.922 & 2.274 & 3.755 & $<0.001$ \\
\hline Unknown & 1.43 & 1.174 & 1.741 & $<0.001$ \\
\hline Facility type & & & & \\
\hline Community Cancer & & & & \\
\hline Program & 1 & & & - \\
\hline Comprehensive & & & & \\
\hline Community & & & & \\
\hline Cancer Program & 0.93 & 0.836 & 1.034 & 0.179 \\
\hline Academic/ & & & & \\
\hline Research Program & 0.512 & 0.458 & 0.571 & $<0.001$ \\
\hline Integrated Network & & & & \\
\hline Cancer Program & 0.852 & 0.746 & 0.972 & 0.017 \\
\hline Unknown & 0.738 & 0.631 & 0.862 & $<0.001$ \\
\hline
\end{tabular}

Multivariate logistic regression for unplanned readmission. 
insurance, including greater wait times, treatment delays, and higher mortality (8-11). Furthermore, surgical delays have been consistently shown to result in increased morbidity and mortality $(12,13)$. In our analysis, unplanned readmission was more prevalent in invasive tumors, with AJCC stages higher than II and Breslow depth greater than $1.01 \mathrm{~mm}$. We speculate that these patients potentially had delayed diagnosis and treatment.

Our study used a large sample taken from the NCDB, which records approximately $70 \%$ of the newly diagnosed cancer patients in the United States. However, studies on national patient databases have limitations that merit consideration, such as the potential for coding errors and a retrospective nature. Moreover, melanoma is a disease that affects primarily white people, making the cohort of other races substantially smaller. Still, the advantage of the multiinstitutional national database allotted in this analysis allows for increased geographic diversity compared to singleinstitution cohort studies. Our large sample size provided enough statistical power for our multivariate analysis adjusted for confounders. We encourage the continued investigation of predictive factors of unplanned readmission to track temporal trends of these patient disparities.

In conclusion, our analysis of predictive factors contributing to unplanned readmission of patients who underwent surgical treatment for melanoma identified higher odds among non-white patients and those living in a zip code with lower average income. The implications of these differences on care delivery are unclear, but should be taken into consideration.

\section{Conflicts of Interest}

The Authors have no conflicts of interest to declare regarding this study.

\section{Authors' Contributions}

DB, MTH, and AJF had full access to all of the data in the study and take responsibility for the integrity of the data and the accuracy of the data analysis. Study concept and design: DB, AJF, ACS, EG. Acquisition, analysis, or interpretation of data: DB, ASP, AJF. Drafting of the manuscript: DB, DJR, MTH, AS. Critical revision of the manuscript for important intellectual content: AAL, SB, MTH, ACS, EG, and AJF. Study supervision: AJF.

\section{Acknowledgements}

Funding: This study was supported in part by the Mayo Clinic Robert D. and Patricia E. Kern Center for the Science of Health Care Delivery, and by the Mayo Clinic Center for Individualized Medicine.

\section{References}

1 Guy GP Jr., Thomas CC, Thompson T, Watson M, Massetti GM and Richardson LC: Vital signs: Melanoma incidence and mortality trends and projections - united states, 1982-2030. MMWR Morb Mortal Wkly Rep 64(21): 591-596, 2015. PMID: 26042651.

2 Gani F, Lucas DJ, Kim Y, Schneider EB and Pawlik TM: Understanding variation in 30-day surgical readmission in the era of accountable care: Effect of the patient, surgeon, and surgical subspecialties. JAMA Surg 150(11): 1042-1049, 2015. PMID: 26244543. DOI: 10.1001/jamasurg.2015.2215

3 Leppin AL, Gionfriddo MR, Kessler M, Brito JP, Mair FS, Gallacher K, Wang Z, Erwin PJ, Sylvester T, Boehmer K, Ting HH, Murad MH, Shippee ND and Montori VM: Preventing 30day hospital readmissions: A systematic review and meta-analysis of randomized trials. JAMA Intern Med 174(7): 1095-1107, 2014. PMID: 24820131. DOI: 10.1001/jamainternmed 2014.1608

4 Al-Qurayshi Z, Srivastav S, Wang A, Boh E, Hamner J, Hassan $\mathrm{M}$ and Kandil E: Disparities in the presentation and management of cutaneous melanoma that required admission. Oncology 95(2): 69-80, 2018. PMID: 29913445. DOI: 10.1159/000468152

5 Ascha M, Ascha MS and Gastman B: Identification of risk factors in lymphatic surgeries for melanoma: A national surgical quality improvement program review. Ann Plast Surg 79(5): 509-515, 2017. PMID: 28650410. DOI: 10.1097/sap.00000 00000001152

6 Bilimoria KY, Stewart AK, Winchester DP and Ko CY: The national cancer data base: A powerful initiative to improve cancer care in the united states. Ann Surg Oncol 15(3): 683-690, 2008. PMID: 18183467. DOI: 10.1245/s10434-007-9747-3

7 Adamson AS, Zhou L, Baggett CD, Thomas NE and Meyer AM: Association of delays in surgery for melanoma with insurance type. JAMA Dermatol 153(11): 1106-1113, 2017. PMID: 28979974. DOI: 10.1001/jamadermatol.2017.3338

8 Amini A, Rusthoven CG, Waxweiler TV, Jones BL, Fisher CM, Karam SD and Raben D: Association of health insurance with outcomes in adults ages 18 to 64 years with melanoma in the united states. J Am Acad Dermatol 74(2): 309-316, 2016. PMID: 26670715. DOI: 10.1016/j.jaad.2015.09.054

9 Fedewa SA, Lerro C, Chase D and Ward EM: Insurance status and racial differences in uterine cancer survival: A study of patients in the national cancer database. Gynecol Oncol 122(1): 63-68, 2011. PMID: 21463888. DOI: 10.1016/j.ygyno.2011.03.010

10 Halpern MT and Holden DJ: Disparities in timeliness of care for u.S. Medicare patients diagnosed with cancer. Curr Oncol 19(6): e404-413, 2012. PMID: 23300364. DOI: 10.3747/co.19.1073

11 Simard EP, Fedewa S, Ma J, Siegel R and Jemal A: Widening socioeconomic disparities in cervical cancer mortality among women in 26 states, 1993-2007. Cancer 118(20): 5110-5116, 2012. PMID: 22707306. DOI: $10.1002 / \mathrm{cncr} .27606$

12 Bilimoria KY, Ko CY, Tomlinson JS, Stewart AK, Talamonti MS, Hynes DL, Winchester DP and Bentrem DJ: Wait times for cancer surgery in the united states: Trends and predictors of delays. Ann Surg 253(4): 779-785, 2011. PMID: 21475020. DOI: $10.1097 /$ SLA.0b013e318211cc0f

13 Korsgaard M, Pedersen L, Sorensen HT and Laurberg S: Delay of treatment is associated with advanced stage of rectal cancer but not of colon cancer. Cancer Detect Prev 30(4): 341-346, 2006. PMID: 16965875. DOI: 10.1016/j.cdp.2006.07.001

Received November 5, 2019

Revised November 11, 2019 Accepted November 12, 2019 